\title{
Interactive comment on "Role of surface hydrology in determining the seasonal cycle of Indian summer monsoon in a general circulation model" by Shubhi Agrawal and Arindam Chakraborty
}

\section{Anonymous Referee \#3}

Received and published: 2 January 2017

General comments: This study starts with showing the precipitation bias between model results and observation datasets during the Indian summer monsoon period, combining with analyzing the vertical moisture stability. Furtherly, the sensitive experiments are conducted to indicate that the effect of remote soil moisture over the WCA contribute more to the precipitation bias in June than that of local ones over the GP. However, about description of the moisture circulation in the remote influence is very confused. First of all, due to the location of GP, how could the intensifying low-level westerly jet (depicted in Fig.9b) influenced by the negative soil moisture over the WCA bring more moisture to GP in June? The southwest wind cannot reach to GP and the

Printer-friendly version

Discussion paper 
wind interacting area locates in the southern part to GP. In addition, the explanation of the low-level jet in the sensitive experiment of WCAGP_NDG should be specific, so does ITCZ. Overall, the soil moisture, especially explaining from its induced moisture circulation, cannot be seen that it can improve the prediction of the onset of the Indian summer monsoon in this study. But the results are promising to advance the GCM simulating the Indian summer monsoon precipitation.

Interactive

comment

Specific comments: 1) Page 6 line 20, 'that is an onset is declared if the area averaged rainfall is more that $4 \mathrm{~mm}$ day -1 for at least five consecutive days after first of June'. This sentence need to be rewrittern. 2) The usage of which and that is not proper, eg. Page 8 line 28 'under extreme conditions, that is very dry surface and completely saturated surface' where' that' should be changed to 'which'. 3) Page 9 line 9, 'though this small. .., but...' where but should be removed. 4) Page 9 line 14, '... weakens the circulation. . 'where 'the circulation' is not very clear. 5) Page 13 line 6, '. . modulate the onset phase and seasonal cycle of Indian summer monsoon' where 'the onset phase' should be specific. 6) About the equations, please give the details of the physical meaning of every alphabet.

Interactive comment on Hydrol. Earth Syst. Sci. Discuss., doi:10.5194/hess-2016-591, 2016.

Printer-friendly version

Discussion paper 